\title{
Risky business? Welfare state reforms and government support in Britain and Denmark
}

Article

Accepted Version

Lee, S., Jensen, C., Arndt, C. and Wenzelburger, G. (2020) Risky business? Welfare state reforms and government support in Britain and Denmark. British Journal of Political Science, 50 (1). pp. 165-184. ISSN 1469-2112 doi: https://doi.org/10.1017/S0007123417000382 Available at https://centaur.reading.ac.uk/73329/

It is advisable to refer to the publisher's version if you intend to cite from the work. See Guidance on citing.

To link to this article DOI: http://dx.doi.org/10.1017/S0007123417000382

Publisher: Cambridge University Press

All outputs in CentAUR are protected by Intellectual Property Rights law, including copyright law. Copyright and IPR is retained by the creators or other copyright holders. Terms and conditions for use of this material are defined in the End User Agreement.

www.reading.ac.uk/centaur 
Central Archive at the University of Reading

Reading's research outputs online 


\title{
Risky business? \\ Welfare state reforms and government support in Britain and Denmark
}

\author{
Seonghui Lee \\ (Department of Political Science, Aarhus University, slee@ps.au.dk) \\ Carsten Jensen \\ (Department of Political Science, Aarhus University, carstenj@ps.au.dk) \\ Christoph Arndt \\ (Department of Political Science, Aarhus University, arndt@ps.au.dk) \\ Georg Wenzelburger \\ (Department of Social Sciences, TU Kaiserslautern, georg.wenzelburger@sowi.uni-kl.de)
}

\begin{abstract}
Are welfare state reforms electorally dangerous for governments? Only recently have political scientists begun to study this seemingly simple question, and existing work still suffers from two shortcomings. First, it has never tested the reform-vote link with data on actual legislative decisions for enough points in time to allow robust statistical tests. Second, it has failed to take into account the many expansionary reforms that have occurred in recent decades. Expansions often happen in the same years as cutbacks. By focusing only on cutbacks, estimates of the effects of reforms on government popularity become biased. In this paper, we address both shortcomings. Our results show that voters punish governments for cutbacks, but also reward them for expansions, making so-called "compensation" a viable blame avoidance strategy. We also find that the size of punishments and rewards are roughly the same, suggesting that voters' well-documented negativity bias does not directly translate into electoral behavior.
\end{abstract}

Keywords: welfare state reforms; government support; unemployment protection; old-age pensions; new politics of welfare state.

Acknowledgements: We want to thank the editor and three reviewers for excellent and very thorough comments. An early version of the paper was presented in the Section of Behavior and Institutions at the Department of Political Science at Aarhus University, as well as at the annual meeting of the MPSA in Chicago. We are grateful for the many critical and thoughtful comments we got on those occasions. Lasse Leipziger and Kristian Nicolaisen provided first-class research assistance. The research has been funded by The Danish Council for Independent Research (grant no. 4003-00013). Replication data are available at XXX and online appendices are available at XXX. 
The welfare state is among the most salient topics in West European electoral politics. ${ }^{1}$ Large segments of the public enjoy the benefits the welfare state brings, and it is something of a truism that governments can get seriously hurt by trimming citizens' social rights. ${ }^{2}$ There is certainly plenty of anecdotal evidence of such electoral punishment, but the findings from more systematic research have been mixed. Indeed, existing research has found that welfare state cutbacks do sometimes, but not always, or only in specific contexts, lead to electoral punishment. ${ }^{3}$

However, given how controversial this consensus is - that most politicians most of the time can get away with cutbacks of the otherwise very popular welfare state - it is warranted to point to two weaknesses of extant research. First, the extant measures of welfare state reform are either too aggregated, indirect, or only applicable to a few cases. None of the existing measurements combines the qualities of recording concrete legislative changes with a large number of years and countries. Second, virtually no study has yet considered the effect of welfare state expansion. A significant amount of expansion has occurred even in the era of so-called permanent austerity since the 1970s, and such expansionist events can easily take place in the same election period as cutbacks. Moreover, we do not know if the effects of expansions and cutbacks are of the same magnitude, or if, as some research would suggest, cutbacks matter more to voters than expansions. ${ }^{4}$ In short, to get an unbiased estimate of the effect of changes in the welfare state on governments' support from voters, both expansions and cutbacks have to be analyzed.

In this article we address both shortcomings. We collect a new dataset on welfare state reforms in pensions and unemployment protection combined with polling data for government support in Britain and Denmark, covering the years 1946-2014 in the former case and 1957-2014

\footnotetext{
${ }^{1}$ e.g., Aardal and van Wijnen 2006.

${ }^{2}$ Pierson 1994; 1996.

${ }^{3}$ e.g., Giger 2011; Giger and Nelson 2011; 2013; Arndt 2013; Elmelund-Præstekær et al. 2015.

${ }^{4}$ Weaver 1986; Pierson 1994; 1996.
} 
in the latter. The two countries are different both in terms of political system and welfare state structure. The data allows us to get a firm understanding of both commonalities and national idiosyncrasies in the effect of welfare state reform on support for government.

Our analysis shows that welfare state reforms affect government support. More precisely, with the exception of unemployment benefits in Denmark, support for government tends to decline as a response to cutbacks and increases as a response to expansions. In years with no expansions, cutbacks have a clear-cut negative effect, but in years with both cutbacks and expansions the negative effect is either neutralized or reversed into a net positive effect. Providing a thorough test of Pierson's “compensation" strategy, our finding provides an answer to the question of why governments are not always punished for cutbacks and, more broadly, whether there is room for politicians today to claim credit for pleasing voters. ${ }^{5}$ Indeed, our results suggest that the reason why the existing literature has found such comparably mixed results is that it has overlooked the fact that governments often successfully claim credit for expansions.

We also show that governments typically do not lose more support from cutbacks than they gain from expansions. This flies in the face of common wisdom, which assumes that voters care more about what is done against them than what is done for them. As we highlight in our discussion, this does not disprove the notion of negativity bias, but rather suggests that voters' psychological biases are not translated as directly into vote intention as previously assumed.

In the following section, we start by outlining the state of the art in research on the link between welfare reform and electoral support, pointing out its achievements and shortcomings. In the subsequent section we deduce three hypotheses to be tested in the remainder of the paper. We then present our original data on welfare reform and discuss our estimation strategy and the relevant issues. After presenting our findings we end the paper by discussing next steps for research in this field.

\footnotetext{
${ }^{5}$ Pierson 1994.
} 


\section{State of the art}

There is little doubt that the welfare state is hugely popular. Large segments of the public believe that it is the government's responsibility to ensure adequate living conditions for the old, sick, and jobless, and it has been repeatedly documented that there is broad-based demand for ever more money to be spent on these areas. ${ }^{6}$ All else equal, such popularity makes cutbacks electorally risky. In the 1990s, this insight fueled the literature on the new politics of the welfare state, most eloquently advocated by Pierson. ${ }^{7}$

According to Pierson, politicians are squeezed between the popular demand for welfare and the need for fiscal austerity. On the one hand, voters will punish governments for cutbacks. On the other hand, public budgets are overburdened, taxation already too high, and debt gradually mounting to unsustainable levels. In such a situation, politicians will primarily do nothing, hoping simultaneously not to upset their voters and that the economy will keep afloat until they themselves are out of office.

Yet the prediction that nothing will happen has not proven correct. New data on the development of citizens' social rights since the 1970s have shown conclusively that the generosity of the welfare state has declined, especially when it comes to unemployment protection. ${ }^{8}$ Given the popularity of the welfare state, the expectation based on the new politics argument would be that governments should have experienced a severe electoral backlash. Surprisingly, this does not appear to have happened.

Armingeon and Giger's pioneer study finds that welfare state cutbacks are not dangerous unless they are made into an issue in the preceding electoral campaign. ${ }^{9}$ Giger and Nelson and

\footnotetext{
${ }^{6}$ e.g., Jæger 2011; Jensen 2014.

${ }^{7}$ 1994; 1996.

${ }^{8}$ Korpi and Palme 2003; Scruggs et al. 2014.

${ }^{9}$ Armingeon and Giger 2008.
} 
Schumacher et al. study the role of party families for punishment, and both conclude that there is no universal cutbacks-punishment function at work. ${ }^{10}$ Giger and Nelson find that religious (mostly Christian democratic) and liberal parties can gain votes from cutbacks, while there are no effects for other party families. Conversely, Schumacher et al. find that social democratic and Christian democratic parties lose votes. All three studies use data from the Comparative Welfare State Entitlements Database on the social rights of citizens. ${ }^{11}$ With this data, it is possible to relate changes in social rights within an election period to changes in vote share from one election to the next. The foremost advantage of the dataset is its wide coverage both temporally and cross-nationally, covering multiple countries over roughly 30 years from the 1970 s to the early 2000s. ${ }^{12}$

The downside of this approach is the aggregated nature of changes and that the measure of social rights does not capture legislative decisions. First, all three studies rely on changes in the replacement rates for benefit recipients as their measure of cutbacks. Replacement rates are the percentage of the average production worker's wage that the unemployed, sick, or pensioners receive in income benefits. Replacement rates are meant to measure the real value of benefits paid out to recipients. Using replacement rates as the measure of welfare reform, however, is problematic in several ways. For one, they may not capture all forms of salient cutbacks.

Reductions in the duration of benefits, qualification period, contribution level, and so on are all ignored by design even though a majority of changes actually relate to these forms of cutbacks, as we will detail below. ${ }^{13}$ This implies that the punishment opportunities are substantially underestimated.

\footnotetext{
${ }^{10}$ Giger and Nelson 2011; Schumacher et al. 2013.

${ }^{11}$ Scruggs et al. 2014.

${ }^{12}$ Recently, new data for the 2002-2011 period was added to the Comparative Welfare State Entitlements Database, but was not included in the studies reviewed here.

${ }^{13}$ See Clasen and Clegg 2007 for a detailed critique.
} 
Second, replacement rates are not a function just of the benefits paid out to recipients, but also, and again by design, of the wage of the average production worker. If the average production worker's wage increases, the replacement rates will by mathematical necessity decrease unless benefits increase simultaneously (since the denominator in the calculation of the percentage grows while the numerator stays the same). In other words, if the economy is doing well and wages are increasing, replacement rates will decline even without any political decision to cut benefits. This is doubly problematic because governments typically are rewarded for a good economy ${ }^{14}$ and there is no blameworthy government action to punish. For these reasons too, using replacement rates is likely to underestimate the effect of cutbacks on government support.

Finally, the implementation of political decisions to change replacement rates does not always happen in the same electoral cycle as the decision occurs. Delays in implementation are, in fact, frequent. This is normally the case with regard to pensions, where changes are implemented several years, or even decades, down the road, and sometimes such delayed implementation also happens for changes in unemployment and sick pay benefits. ${ }^{15}$ This means that the current government might not be to blame for reductions in benefits that may have been decided decades ago. That might not stop voters from blaming the government anyway, of course, but still points to a problem of identifying the causes of governments' popularity. In addition, many voters have poor insight into their benefits and how they change over time. Given this, it is often the parliamentary decision to make cuts that attracts negative attention rather than the implementation itself. ${ }^{16}$

Armingeon and Giger, Giger and Nelson, Schumacher and colleagues and several other articles examine the effect of cutbacks on the government's vote share at the next election. ${ }^{17}$

\footnotetext{
${ }^{14}$ e.g., Lewis-Beck and Stegmaier 2000.

${ }^{15}$ Pierson 1994; Green-Pedersen 2004.

${ }^{16}$ Pierson 1994.

${ }^{17}$ Armingeon and Giger 2008; Giger and Nelson 2011; Schumacher et al. 2013.
} 
Exploring the punishment-reward mechanism through electoral vote choice is clearly a valid choice, as elections are the foremost venue for voters to attribute political responsibility. There is, in other words, nothing wrong with such a strategy in itself, but again it risks overlooking punishment. Voters may react at the time of a decision, but later events in the electoral cycle such as an improving economy may crowd out the initial negative reaction to cutbacks. Put differently, an insignificant association between cutbacks and election outcomes can be caused by two things: that voters did not react, or that they in fact did react, but later events watered-down the effect. Whether or not that reaction carries over into the actual election outcome is clearly also important, but remains secondary to the more fundamental question: do voters even respond? Of course, the answer to this question is less interesting if the reaction only last for, say, one week. Yet if punishments last into the medium term, for instance one year, this must be considered substantial because it is likely to affect the way the government will behave (e.g., not proposing new cutbacks, launching initiatives in other policy domains to distract voters, or reshuffling the members of the cabinet).

Another set of empirical studies focuses on a smaller number of cases using micro-level data. ${ }^{18}$ This allows researchers to link concrete legislative action with the reactions of voters, creating a fine-grained picture of the relationship between cutbacks and government popularity. These studies conclude that voters' reaction is dependent on the context of the decision: sometimes governments are punished, but sometimes not. The downside of this small-N approach is that it is difficult to establish whether there are any general, or average, effects of cutbacks. More critically, with a small number of cases it is never possible to rule out potential confounders such as the state of the economy or how long the government has been in office (i.e., the so-called "cost of ruling" effect).

\footnotetext{
${ }^{18}$ e.g., Arndt 2013; Davidson and Marx 2013; Lindbom 2014; Elmelund-Præstekær et al. 2015.
} 
A commonality of virtually all existing studies is that they look at cutbacks only. This draws on what Pierson in his landmark work highlighted as the core issue of modern-day welfare state politics. Decades ago, in the Golden Age of the welfare state, expansion was the name of the game, but since the late 1970s, the need for fiscal austerity has ruled out expansions. Policy change, according to the literature, almost always equals cutbacks. Politicians can consequently never claim credit for popular actions (thereby winning new votes), and hope only to avoid blame for unpopular ones (hoping not to lose the votes they already have).

However, as we will show below, expansions continue to occur almost with the same frequency as cutbacks, at least outside the area of unemployment protection. This is vital for several reasons. First, in substantive terms it means that there are many credit-claiming opportunities unaccounted for. A few existing studies suggest that governments under certain conditions can gain votes from cutbacks. ${ }^{19}$ Yet the much more obvious credit-claiming opportunity - expanding the generosity of social rights - has never been considered. Second, from a methodological perspective, by not including the (many) instances of expansion, the explanatory variable (welfare reform) is truncated to a subset of real-life observations. ${ }^{20}$ Third, in years with cutbacks there may or may not also be expansion, and vice versa. Even if we assume that expansion does not have quite as strong a positive effect on government support as the negative effect of cutbacks, as long as expansion has any effect on government support, the statistical models not accounting for expansions are misspecified.

Thus, despite substantial advances in the literature during the past decade, there are still some unsettled questions. To move the field forward we need data that fulfills five criteria. The data should (1) contain legislative decisions (2) relating to all aspects of welfare state generosity

\footnotetext{
${ }^{19}$ Giger and Nelson 2011; Elmelund-Præstekær and Emmenegger 2013.

${ }^{20}$ The works of Armingeon and Giger, Giger and Nelson, Schumacher and colleagues, for instance, code cutbacks as " 1 " and status quo and expansions as " 0 ". When both status quo and expansion are coded together as " 0 ", years (or election cycles) without any reforms are treated as identical to years (or election cycles) with expansions, making it impossible to assess the independent effect of expansions.
} 
and not just benefit levels, (3) include both cutbacks and expansions, (4) cover enough observations to control for possible confounders and (5) relate this to medium-term changes in government support. We present a dataset that meets these five criteria in Section 3.

\section{Hypotheses}

The previous section hinted at a set of theoretical questions that have been glossed over, or not satisfactorily answered, because of the lack of appropriate data. Most basically, we still need to assert if cutbacks are punished by voters or not. Previous research has provided some insights, but given their methodological limitations a test of Pierson's core proposition remains warranted. This leads to our first hypothesis:

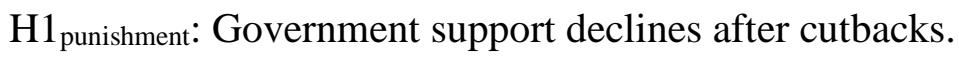

Apart from this baseline hypothesis, two issues that both relate to the potential for blame avoidance are of particular relevance. ${ }^{21}$ First, the fact that politicians not only cut in citizens' welfare, but also expand it, raises the prospect that politicians can engage in a so-called "throw good money after bad" ${ }^{22}$ or compensation ${ }^{23}$ blame avoidance strategy. Under this strategy, voters remain supportive of the government because they are getting an expansion to compensate for their loss. Although clearly not a very cost effective strategy, it can help politicians re-calibrate the welfare state without risking their own re-election. The electoral effect of such compensation has never been tested, which inspires the second hypothesis:

\footnotetext{
${ }^{21}$ For reviews of the the literature on blame avoidance, see Hinterleitner 2015 and Vis 2016.

${ }^{22}$ Weaver 1986.

${ }^{23}$ Pierson 1994.
} 
$\mathrm{H} 2$ compensation: The loss in government support from cutbacks is reduced when cutbacks occur together with expansions.

Second, one reason voters may not be persuaded by such compensation attempts, is the tendency for people to ascribe more importance to losses than to gains. Such negativity bias is well-known in psychology ${ }^{24}$ and has been suggested by both Weaver and Pierson to be present in the context of welfare reforms too. ${ }^{25}$ In this perspective, voters care more about what is done against them than what is done for them. If this is the case, an expansion should, in other words, matter less than a cutback for government popularity. Although this expectation certainly appears plausible, and to a large extent is regarded as common wisdom in the literature, it, too, has never been put to the test. Our third hypothesis therefore becomes:

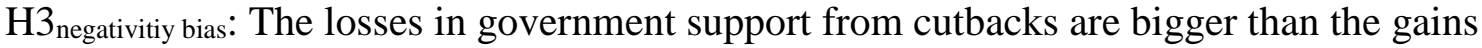
from expansions.

In the rest of the paper we test these three hypotheses. We begin by accounting for our new dataset.

\section{A new dataset on welfare state reform in Britain and Denmark}

Our dataset contains information on legislative changes in the social rights of citizens with regard to old-age pensions and unemployment protection in Britain and Denmark. The two programs were selected for three reasons. First, they constitute a core part of what is conventionally understood as "the welfare state" and, as a result, are prominently featured in a very long list of

\footnotetext{
${ }^{24}$ e.g. Rozin and Royzman 2001.

${ }^{25}$ Weaver 1986; Pierson 1994.
} 
publications on the politics of the welfare state. They also form the backbone of the Comparative Welfare State Entitlement Database that Armingeon and Giger, Giger and Nelson, and Schumacher and colleagues, among others, rely on. ${ }^{26}$ Second, despite our general expectation about cutbacks and expansions hypothesized above, the effect of pension reform might be different from that of unemployment benefits. It is well-evidenced that social protection for the jobless is much less popular among the general public than social protection for the old and the sick. ${ }^{27}$ This suggests the possibility that voters' reactions to welfare reforms might be slightly different depending on the domain of reforms. Third, both programs are transfer schemes, meaning that we can code them using the same codebook, which is important if we want to compare the two programs. Britain and Denmark were chosen because they are characterized by very different political systems. ${ }^{28}$ Britain is the prototypical Westminster system with normally just two large parties in Parliament and single party rule. Denmark, in contrast, is a multiparty system boasting minority governments.

For the dataset we code all legislative changes (what we call reform events) relating to any of the following 13 aspects of citizens' social rights:

1. Qualification period: How long does it take for a person to become eligible?

2. Contribution period: How long must a person contribute to a scheme before becoming eligible?

3. Contribution level: How much must a person contribute?

4. Waiting period: How long after a social risk occurs before a person is eligible?

5. Age brackets: How old must a person be to be eligible?

6. Means test: Is there a means test?

7. Duration period: How long can a recipient receive benefits?

8. Benefit level: Nominal value. What is the nominal value of the benefits?

\footnotetext{
${ }^{26}$ Armingeon and Giger 2008; Giger and Nelson 2011; Schumacher et al. 2013.

${ }^{27}$ van Oorschot 2006; Jensen 2014; Jensen and Petersen 2017.

${ }^{28}$ Lijphart 1999.
} 
9. Benefit level: Indexation rule. Are the nominal benefits automatically regulated and with what factor?

10. Benefit level: Assessment base. Has the base for calculating benefits changed?

11. Employability: Is the recipient required to or offered the opportunity to voluntarily participate in activities meant to increase the likelihood of getting a job?

12. Health documentation: Is the recipient required to document that she is unable to work?

13. Residence: Does it matter where and under what circumstances the recipient lives?

For each of the 13 dimensions we identified whether the reform event implied a cutback or an expansion in citizens' social rights. For example, in 1995 the British government reduced the maximum duration of unemployment insurance benefits from one year to six months. This is coded as a cutback in the duration period (no. 7 in the list above). The same year, the British government increased the pension age for women from 60 to 65 years. This is coded as a cutback in social rights relating to age brackets (no. 5 in the list). We also coded whether a new scheme was created or abolished. There are not many of these events and the subsequent analyses are not affected by whether we include them alongside the regular reform events (i.e., assuming that the creation of a scheme is equivalent to an expansion of social rights and that the abolishment is equivalent to a cutback), or if we simply leave out this category of events. To gather information about reforms, we collected as many secondary sources as possible and supplemented these searches in legislative databases when necessary. ${ }^{29}$

Figures 1-4 display the reform events of the two programs in Britain and Denmark. As we explain below, we were able to obtain data on government popularity back to 1946 in Britain and 1957 in Denmark, so these years also mark the beginning of our reform event data. Figure 1

\footnotetext{
${ }^{29}$ The coding was conducted by a team of trained research assistants and all coding decisions were subsequently controlled by a senior researcher. In the event the senior researcher did not agree with the original coding, the relevant research assistant and senior researcher discussed the coding decision in detail to reach agreement; however, there were only a small number of such instances. Further details regarding the coding scheme and data sources are found in Online Appendix B.
} 
shows British unemployment protection with the number of reform events listed on the vertical axis on the left-hand side. The values on the y-axis represent the number of reform events: the number of expansions above the zero and the number of cutbacks below the zero line. The solid line tracks the development of expansionist reform events over time, while the dashed line tracks the development in reductions.

Figure 1. Reform events in unemployment protection in Britain 1946-2014

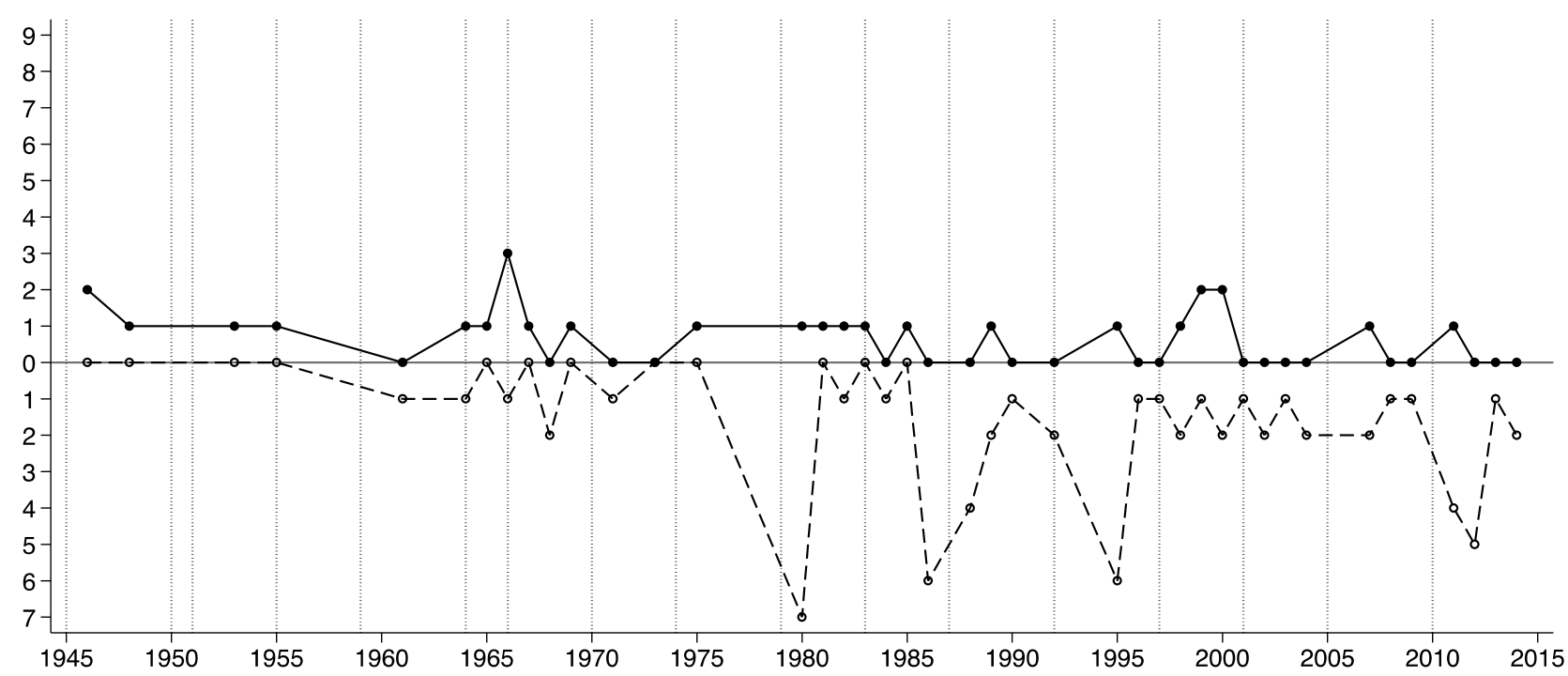

Note: The black circles with the solid line connecting them represent expansionist reform events. The hollow circles with the dashed line represent reductions. The number of reform events is reported on the vertical axis. The thin vertical dashed lines (i.e., in 1945, 1951, 1955, and so on) represent election years.

There are several things worth noting in Figure 1. First, in the first roughly 20 years, only expansion takes place. For instance, in 1946 the National Insurance Act and the Industrial Injuries Act were both established (yielding the count of two expansion events in that year); in 1948 the National Assistance Act was passed (a count of one); in 1953 the maximum period one could receive unemployment benefits was extended from 6 to 19 months (again a count of one); and so on. Second, the transformative nature of the Thatcher era is clearly visible. As many other researchers have pointed out before, since 1979 the generosity of British unemployment benefits 
has been systematically cut. Third, the role of the incumbent's ideology is also clearly visible. All the major instances of cutbacks have occurred under Conservative rule in 1980, 1986, 1988, 1995, 2011 and 2012.

Figure 2. Reform events in old-age pensions in Britain 1946-2014

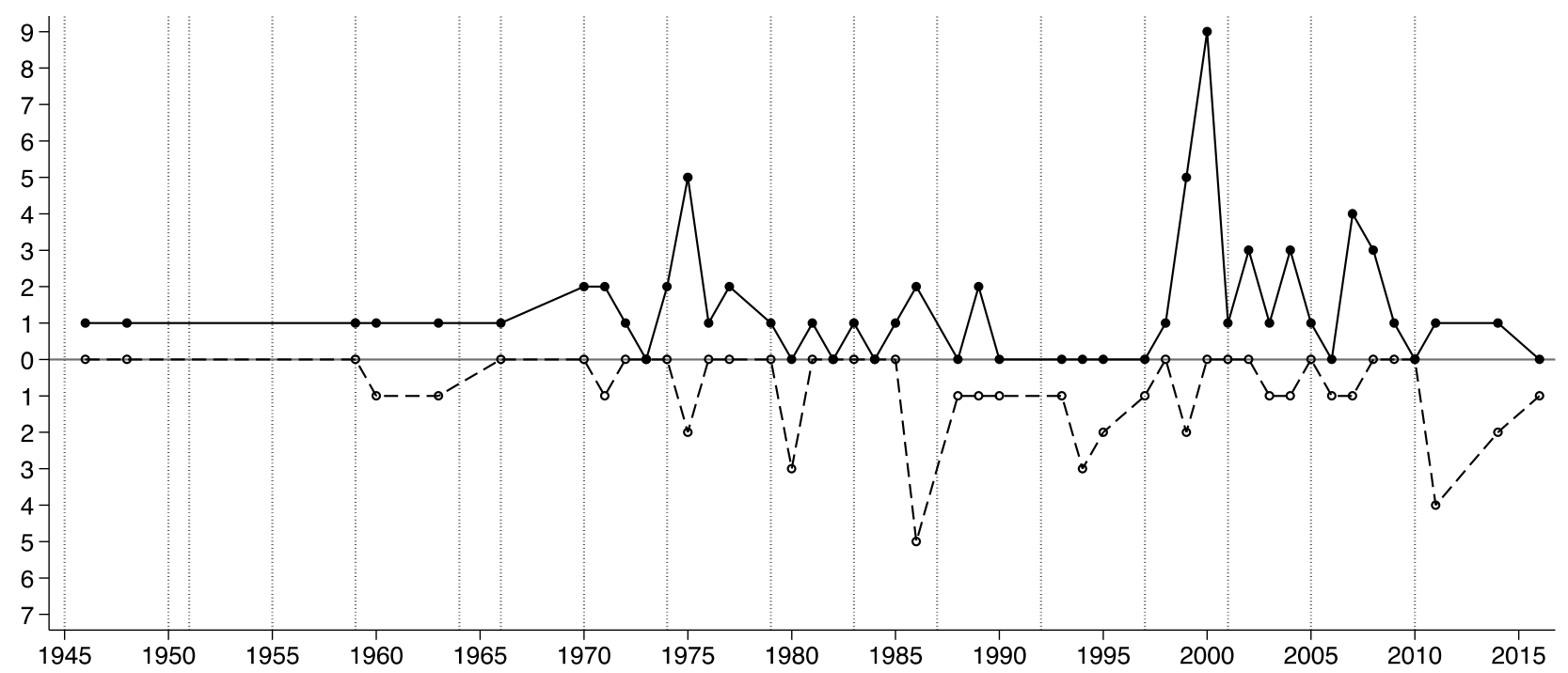

Note: See Figure 1 for details.

Moving from unemployment protection to old-age pensions, Figure 2 reveals important differences. In the first 30 years or so, the picture is much the same as for unemployment protection; namely just a few, mostly expansionist, events. From the 1970s reform activities build up. While the tendency towards cutbacks was obvious for unemployment, it was much more mixed for pensions. Most notable are the expansions under the Labour governments from 1997 to 2010, but expansionist reforms took place from time to time under all governments since the 1970s. This picture of a balance between expansions and reductions fits well with what we know about the development of their generosity from other sources. According to the Comparative Welfare State Entitlements Database, for instance, the overall generosity of old-age pensions has not declined since the 1970 s - in marked contrast to unemployment generosity. ${ }^{30}$

\footnotetext{
${ }^{30}$ Scruggs et al. 2014.
} 
Figure 3. Reform events in unemployment protection in Denmark 1957-2014

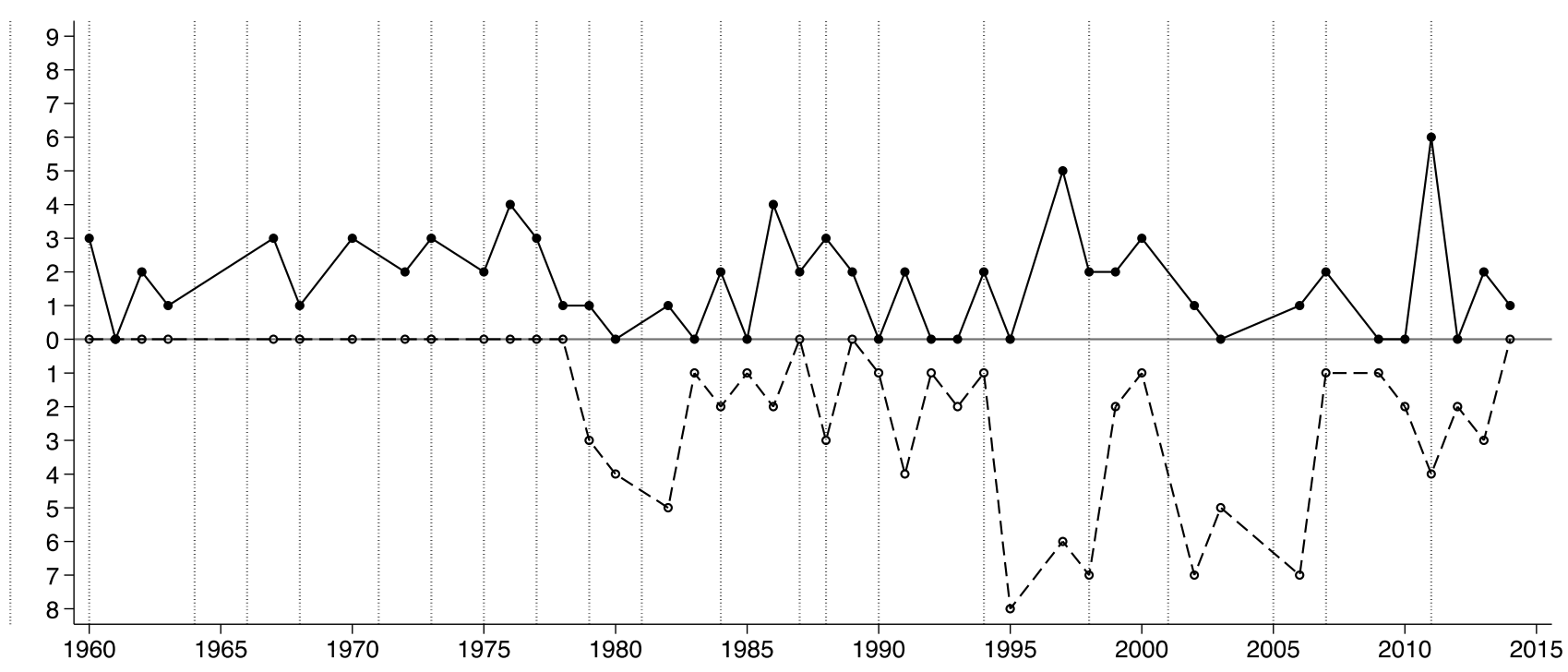

Note: See Figure 1 for details.

Figure 4. Reform events in old-age pensions in Denmark 1957-2014

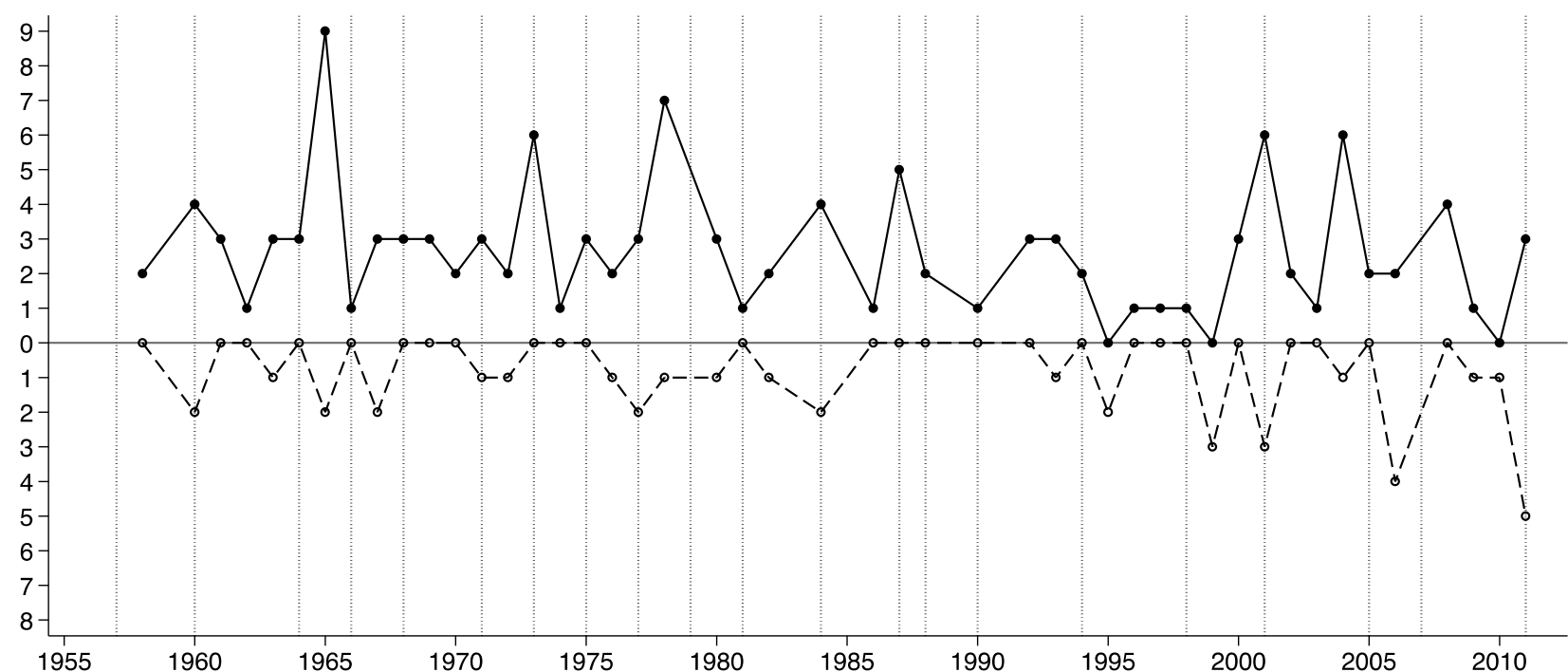

Note: See Figure 1 for details.

Figures 3 and 4 display the data for Denmark. In Figure 3 the reform events in unemployment protection exhibit a pattern similar to the British. All reform events that occurred until the 1970s were expansions, at which point began a shift towards a new regime of cutbacks. 
In contrast to the British case, however, both left- and the right-wing governments introduced cutbacks, although it is worth noting that many of the cutbacks under the right-wing governments of the 2000s were aimed at labor market outsiders and immigrants rather than native Danes. ${ }^{31}$

In Figure 4 we once again see how old-age pensions have developed very differently. The last couple of decades have seen some cutbacks - in 1998, 2006, and 2011 in particular - but there have been many expansions as well. In 2004, for example, the means test for the pension supplement was relaxed, the so-called aeldrecheck (literally "elder check"; an income supplement) made more generous, and a heat supplement was also made increased, while mandatory contributions to a special pensions fund were suspended.

In summary, Figures 1-4 reveal that there have been plenty of credit-claiming opportunities in both Britain and Denmark, even in the era of fiscal austerity where supposedly only cutbacks should have been on the table (although there have been many of those too). We use the number of cutback and expansion reform events as our main explanatory variable to examine how welfare reforms influence government support. ${ }^{32}$

\section{Data, measurements, and estimation strategy}

To examine whether the reform events have had any impact on government popularity, we compiled opinion polls that asked voters who they would vote for if there were an election tomorrow. The annual mean of the polling results for party/parties in government is our main dependent variable, the support for the government. ${ }^{33}$ The annually structured dataset allows us

\footnotetext{
${ }^{31}$ See Arndt 2016.

${ }^{32}$ Some readers might raise a question about the validity of the measurement, such that: Does the number of reform events reflect the magnitude of welfare reforms? We have documented the relevant discussion and additional analyses for the validity check in Online Appendix C.

${ }^{33}$ We obtained monthly polling data from Gallup (1943-2001) and YouGov (2001-2014) for the UK, and from Politisk Indeks (1957-2011) and Søren Risbjerg Thomsen's data (2012-2015) for Denmark. While we use the annual mean of support for governing parties as the main dependent variable, we also tested the hypotheses using slightly different ways of aggregation: by taking median value and midpoint value of monthly polling results. The robustness tests are reported in Online Appendix D.
} 
to see if a reform event in any given year had an effect on the support for the government in the following year. A year is, as the saying goes, a long time in politics and if the effect persists for that long, it should be regarded as substantial - especially, of course, if the size of the effect is large.

Figure 5 displays the support for British governments in the period under study. The black circles with solid lines represent the support for governments led by Labour and the hollow circles with dashed lines by the Conservatives. Apart from the well-known fact that British governments rarely have a majority of the voters behind them, it also transpires that the cost of ruling is at work. As a general tendency, governments loose popularity as time goes by, although they can bounce back, as Thatcher did from her low in 1982 (because of the Falklands war). Figure 6 shows the popularity of the Danish governments as the sum of the average support for the parties that comprised them. That Denmark tends to be run by minority governments is easy to detect, as is the cost of ruling, which, if anything, is even more evident here than in Britain.

Figure 5. Government support in Britain 1946-2014

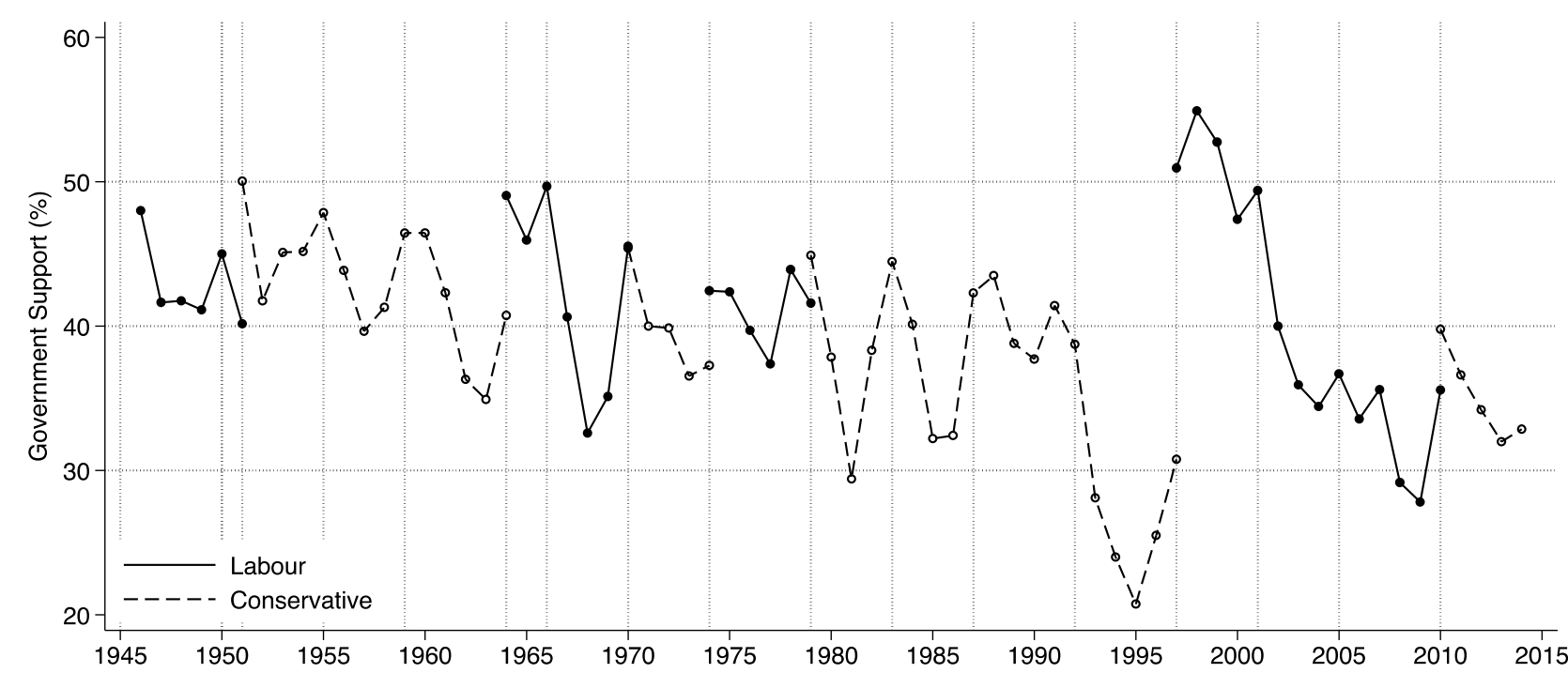

Note: The vertical axis reports the percentage of respondents saying that they would vote for the government if there were an election tomorrow. The thin, dashed vertical lines are election years. Black circles with solid lines represent Labour governments. Hollow circles with dashed lines represent Conservative governments. 
As our main interest is in the estimation of the effect of reform events on government popularity, our specification draws on the standard economic voting models that predict government popularity and party support. ${ }^{34}$ In so doing, we control for the variables that might affect both the reform events and government popularity. The economic situation is one such variable. There is a substantial body of research showing that a bad economy influences the likelihood of reforms occurring, ${ }^{35}$ but also that voters take the economic situation into account when deciding whether or not to vote for the incumbent. ${ }^{36}$ This suggests that the relationship between reform events and government support could be affected by the state of the economy. To control for this, we include measures of real GDP growth, the inflation rate, and the unemployment rate.

Figure 6. Government support in Denmark 1957-2014

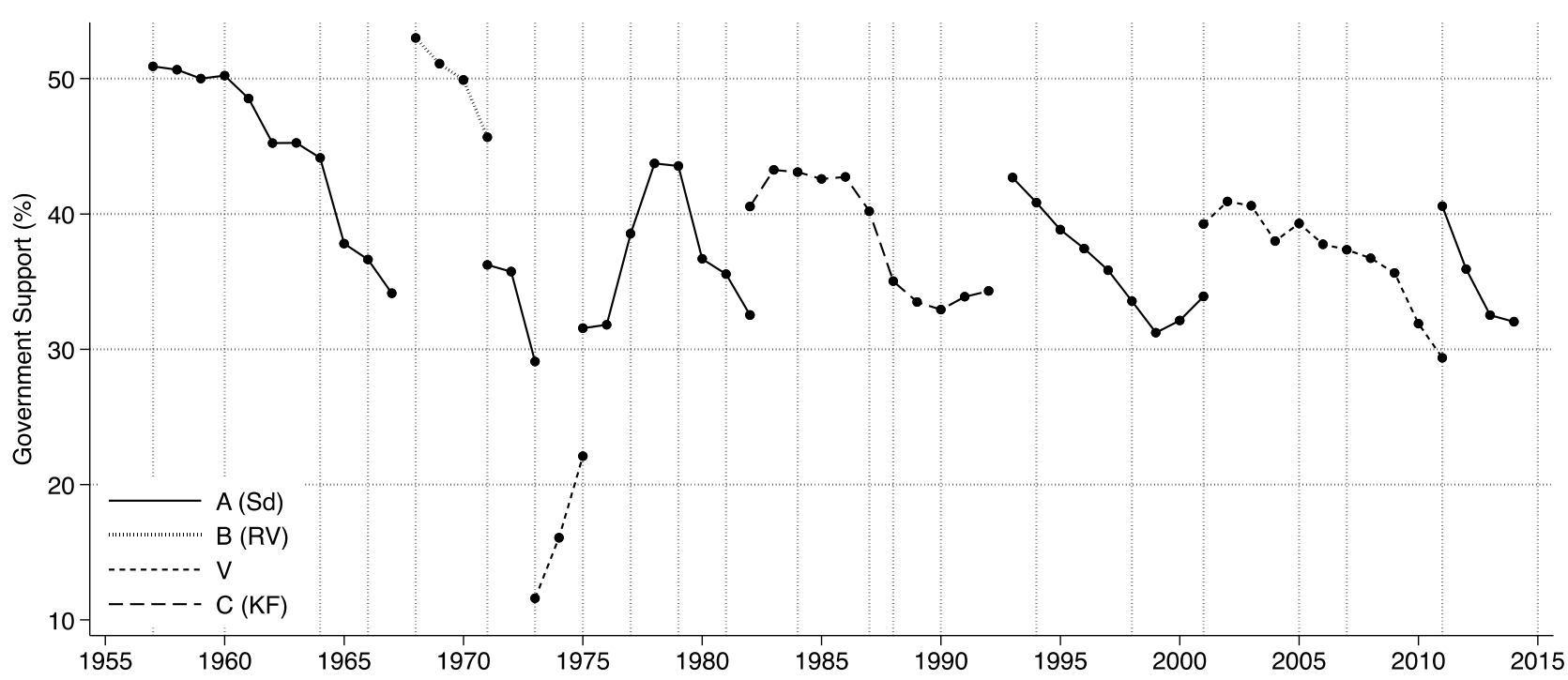

Note: The vertical axis reports the percentage of respondents saying that they would vote for a party in the government if there were an election tomorrow. Legend indicates the party of the Prime Minister. A: Social Democratic Party, B: Social Liberal Party, V: Liberal Party, C: Conservative People's Party.

\footnotetext{
${ }^{34}$ e.g., Lewis-Beck et al. 2004; Sanders 2005; Yantek 1985.

35 e.g., Amable et al. 2006; Jensen and Mortensen 2014.

${ }^{36}$ Lewis-Beck and Stegmaier 2000.
} 
As noted before, governments tend to lose votes as time goes by. This is the welldocumented cost of ruling. ${ }^{37}$ There is also research suggesting that governments tend to enact cutbacks early in the electoral cycle to avoid punishment from voters. ${ }^{38}$ Taken together, we need to control for the number of years a government has been in office since this affects both the likelihood of reform and its popularity. For Denmark we also control for the number of parties in the cabinet. Work by Bawn and Rosenbluth suggests that governments with many parties tend to spend more than governments with fewer parties. ${ }^{39}$ Governments with more parties will, all else equal, also be bigger, which entails that we risk a biased estimate if we do not control for number of cabinet members.

Given the data structure we build, it is necessary to consider the temporal dynamics in the data. As for the reform events, Figures 1-4 demonstrate that the number of reform events in a given year is independent of the number of reform events in the year before. There is also no theoretical reason to expect that having or not having a reform in one year should matter for the likelihood of a reform in the following year. As for our dependent variable, there is a tendency for sliding popularity within each government, i.e., the cost of ruling. We handle this temporal trend in government support by including the cost of ruling as a control variable to de-trend the vote share within each government. Cost of ruling is coded as the number of years a given government was in office since the last election. In our analysis, this variable runs from 1 to 4 in Denmark and to 5 in the UK, the maximum legal length of an election term. ${ }^{40} \mathrm{We}$ do not include

\footnotetext{
${ }^{37}$ Nannestad and Paldam 1994.

${ }^{38}$ Pierson 1994.

${ }^{39}$ Bawn and Rosenbluth 2006.

${ }^{40}$ We have measured this variable in two different ways 1) by disaggregating the continuous variable "cost of ruling" into dummy variables that indicate the year since the government is elected, and 2) by generating two dummy variables for the first year and the second year of the government in order to indicate honeymoon period more directly. The results are reported in Table A3 in the Online Appendix A.
} 
a lagged dependent variable in our regression models because the dependent variable does not share unit roots (i.e., the trend over the entire period is stationary, as can also be seen from Figures 5 and 6). ${ }^{41}$ The regressions are estimated with robust standard errors clustered around the different government parties. ${ }^{42}$ All independent variables except cost of ruling are lagged one year so we can see whether the effects of reforms persist into the medium term. With these methodological issues addressed, we now turn to the findings.

\section{Findings}

Table 1 reports the results for Britain. We estimate four models with Model 1 and 2 focusing on pension reforms and Model 3 and 4 on unemployment protection. Model 1 and 3 only contains the two main variables of interest, namely the number of expansion and cutback events. Model 2 and 4 includes the controls. Since the consistent time series variables for the economy indices are only available since 1960, the full models cover years after 1960.

\footnotetext{
${ }^{41}$ The Dickey-Fuller tests found no unit roots for 1- and 2-lags. Strictly speaking, our data are time-series within a party-government, but not for the entire period due to the existence of multiple cut points (discontinuity) in times of elections or government changes. For more on the risk of using lagged dependent variables for mixed models with longitudinal panel data, which we employ in this paper, see Keele and Kelly (2006).

${ }^{42} \mathrm{We}$ clustered errors by the party of prime minister in Britain (Labour and Conservative party). For Denmark, the cluster is based on three types of coalition governments: Pure left-wing; a cooperation between a red and blue party (e.g. the Grand Coalition between the Social Democratic Party and the Liberal Party in 1978/79); or pure right-wing. We have replicated our main models including government ideology as a control variable. The results are reported in Table A1 in Online Appendix A.
} 
Table 1. Welfare reforms and government support in Britain, 1946-2014

\begin{tabular}{lcccc}
\hline & \multicolumn{2}{c}{ Pensions } & \multicolumn{2}{c}{ Unemployment } \\
& Model 1 & Model 2 & Model 3 & Model 4 \\
\hline Expansion & 0.771 & $0.705+$ & $2.440^{* *}$ & $2.286^{* *}$ \\
& $(0.517)$ & $(0.424)$ & $(0.696)$ & $(0.326)$ \\
Cutbacks & $-1.985^{* *}$ & $-1.211^{* *}$ & $-1.280^{* *}$ & $-0.584^{* *}$ \\
& $(0.097)$ & $(0.389)$ & $(0.050)$ & $(0.170)$ \\
Cost of ruling & & $-1.542^{* *}$ & & $-1.485^{* *}$ \\
& & $(0.027)$ & & $(0.162)$ \\
Real GDP growth & & $0.553^{*}$ & & $0.540^{* *}$ \\
& & $(0.247)$ & & $(0.171)$ \\
Inflation & & $0.174^{* *}$ & & $0.153^{* *}$ \\
& & $(0.009)$ & & $(0.011)$ \\
Unemployment rate & & $-0.470^{* *}$ & & $-0.494+$ \\
Constant & & $(0.087)$ & & $(0.292)$ \\
& $39.069^{* *}$ & $41.445^{* *}$ & $39.044^{* *}$ & $41.401^{* *}$ \\
\hline Observations & $(1.011)$ & $(0.554)$ & $(0.288)$ & $(1.314)$ \\
$\mathrm{R}^{2}$ & 68 & 53 & 68 & 53 \\
\hline
\end{tabular}

Note: Standard errors in parentheses. $+\mathrm{p}<0.10, * \mathrm{p}<0.05, * * \mathrm{p}<0.01$. All variables lagged one year except for cost of ruling.

Overall, the four models indicate relatively strong voter reactions to reforms. Although expansions of pensions are not significantly associated with government's popularity in Model 1, the association turns significant in Model 2 at $\mathrm{p}<0.10$ level after controlling for the cost of ruling, real GDP growth, inflation, and unemployment rate. The estimated coefficient suggests that one expansion increases government support with 0.7 percentage points, which is a sizeable effect also given that many years see more than one expansion event. Moving to the domain of unemployment protection, the positive effect of an expansion is even larger, though it should be stressed that there are not many expansions overall in unemployment protection (cf. Figure 1). The results indicate that a single positive reform event leads to a 2.5-2.8 percentage point increase in government popularity, suggesting that there is ample opportunity for credit-claiming in both policy domains. 
The results indicate that the effect of cutbacks is, again, quite sizeable. Moreover, the effects of cutbacks are consistently significant and negative across both domains, as expected in H1. For pensions the effect in the full model (Model 2) is 1.2 percentage point loss per reform event, down from 1.9 percentage point in the stripped-down model (Model 1). For unemployment protection the estimated effects are more sensitive to the inclusion of controls, but a single reform still entails a 0.6 percentage point loss in government popularity in the full model (Model 4). This remains a quite consequential effect exactly because cutbacks in unemployment protection have happened more frequently than any of the other outcomes (cf. Figures 1 and 2). These findings lend support to H1: British voters do react to cutbacks.

The full models that include control variables account for around a third of the variation in government support (Models 2 and 4), and the stripped-down models (Models 1 and 3) explain between 10 and 13 percent of the variation. Although many other factors might affect a government's popularity, it is noteworthy that our measures of expansions and cutbacks themselves can explain around 10 percent of the variation in government support.

As mentioned previously, one of the shortcomings of the existing literature is that it does not empirically take well into account both expansions and cutbacks even though both Weaver (1986) and Pierson (1994) emphasize that a potential blame avoidance strategy may be to "throw good money after bad" or "compensate" by counter-balancing a cutback with an expansion (as summarized in $\mathrm{H} 2$ ). The empirical problem, in other words, is not just that both cutbacks and expansions matter. As we have shown so far, it is that there is great variation across years whether the reform events are purely expansionary, only cutbacks, or both at the same time. Focusing exclusively on cutbacks, as the empirical literature has done, risks producing a biased estimate. To illustrate this, we have calculated the net effects of one and two cutbacks in a year, respectively, when zero, one, or two expansion events occurred in the same year. Some of these scenarios do not occur in the data, or only do so in very few instances, in which case we refrain 
from calculating the marginal effects (and report an N/A instead). Thus, we report the estimated effects of reform events in Table 2 only for the scenarios that may be considered realistic.

Table 2. Net effects of expansions and cutbacks in Britain

\begin{tabular}{llccc}
\hline & & \multicolumn{3}{c}{ Expansion events } \\
& & & 1 & 2 \\
\cline { 3 - 4 } & 0 & (baseline) & $0.705^{*}$ & $1.410^{*}$ \\
& 1 & $-1.211^{* *}$ & -0.506 & 0.199 \\
Cutback events & 2 & $-2.421^{* *}$ & -1.716 & $\mathrm{~N} / \mathrm{A}$ \\
\cline { 3 - 5 } & & \multicolumn{3}{c}{ Unemployment } \\
\cline { 3 - 4 } & 0 & (baseline) & $2.286^{* *}$ & $4.570^{* *}$ \\
& 1 & $-0.584^{* *}$ & $1.701^{* *}$ & $3.987^{* *}$ \\
& 2 & $-1.169^{* *}$ & $1.117^{* *}$ & $3.403^{* *}$ \\
\hline
\end{tabular}

Note: Calculated based on the full models in Table 1 (Models 2 and 4). Net effects marked with ** statistically significant with $\mathrm{p}<0.05$, and $*$ with $\mathrm{p}<0.10$. N/A means that the coefficient is not reported because the scenario does not occur in our data.

In the left-most column the effect of cutbacks with no counter-balancing expansions is reported. Across the two policy areas (pensions and unemployment) and the number of cutbacks (one or two) there is a clear-cut negative effect of cutbacks on governments' support. The negative effect varies in size across the policy areas as we would expect from the results in Table 1 , but in all cases the coefficient is non-negligible and statistically significant. Yet when there is just a single expansion event, the results alter dramatically. Looking first at pensions, a single expansion entirely neutralizes the effect of a cutback. The compensation effect is more pronounced for unemployment. A single expansion event even overpowers the effect of single cutback and neutralizes that of two cutbacks. The British data clearly supports our expectation, summarized as $\mathrm{H} 2$, that expansion events compensate the loss due to cutbacks. ${ }^{43}$

\footnotetext{
${ }^{43}$ We did run additional models that interacted expansions with cutbacks. These did not substantially change the explained variance of the models and the predicted values for government support in the multiplicative specifications did not differ much from the linear additive models presented here. We therefore decided to go with the more parsimonious specification without an interaction.
} 
Table 3. Welfare reforms and government support in Denmark, 1957-2014

\begin{tabular}{|c|c|c|c|c|}
\hline & \multicolumn{2}{|c|}{ Pensions } & \multicolumn{2}{|c|}{ Unemployment } \\
\hline & Model 5 & Model 6 & Model 7 & Model 8 \\
\hline \multirow[t]{2}{*}{ Expansions } & $0.788+$ & $0.889 *$ & -0.181 & $-0.622 * *$ \\
\hline & $(0.421)$ & $(0.413)$ & $(0.614)$ & $(0.144)$ \\
\hline \multirow[t]{2}{*}{ Cutbacks } & -0.467 & $-0.394^{*}$ & -0.438 & -0.090 \\
\hline & $(0.779)$ & $(0.163)$ & $(0.690)$ & $(0.327)$ \\
\hline \multirow[t]{2}{*}{ Cost of ruling } & & 0.102 & & -0.553 \\
\hline & & $(0.623)$ & & $(0.383)$ \\
\hline \multirow[t]{2}{*}{ Real GDP growth } & & $0.674 * *$ & & $0.705 * *$ \\
\hline & & $(0.169)$ & & $(0.083)$ \\
\hline \multirow[t]{2}{*}{ Inflation } & & -0.017 & & -0.049 \\
\hline & & $(0.574)$ & & $(0.601)$ \\
\hline \multirow{2}{*}{ Unemployment rate } & & -0.417 & & -0.588 \\
\hline & & $(0.523)$ & & $(0.403)$ \\
\hline \multirow[t]{2}{*}{ Number of cabinet parties } & & $3.682 * *$ & & $3.834 * *$ \\
\hline & & $(1.270)$ & & $(1.219)$ \\
\hline \multirow[t]{2}{*}{ Constant } & $36.686 * *$ & $27.499 * *$ & $38.717 * *$ & $31.203^{* *}$ \\
\hline & $(1.541)$ & (1.984) & $(2.808)$ & $(1.718)$ \\
\hline Observations & 53 & 49 & 53 & 49 \\
\hline $\mathrm{R}^{2}$ & 0.044 & 0.447 & 0.022 & 0.410 \\
\hline
\end{tabular}

Table 3 shifts attention to Denmark. Looking first at pensions, roughly the same picture emerges as for Britain. An expansion is rewarded with an increase in support of almost one percentage point in both Models 5 and 6. Cutbacks have a negative effect when controlling for confounders, but the size of the effect is a comparably low 0.4 percentage points, though still statistically significant and non-negligible in size. This gives a hint that blame diffusion is easier in the Danish political system since the support of Danish governments (usually minority) typically slips less than the support for British governments (always majority). Still, on balance the results from pension reforms in Denmark lend support to H1.

Moving to unemployment protection, the results are rather interesting. In the strippeddown model (Model 7) we find no significant effect of expansions or cutbacks. Yet when controlling for the confounders there is a negative effect of expansions (Model 8). This negative 
effect of expansions is something of a puzzle. As noted above, it is well-known that unemployment protection is less popular with the public than old-age pensions, in Denmark as well as in Britain. However, the fact that Danish unemployment benefits and conditions are much more generous than the British might play a role. Unemployment benefits almost always go to a small and relatively marginal group, and if the Danish public believes that benefits are already high, a government's attempt to expand them could be perceived as a waste of money. While this is not quite within the range of present study, whether the negative effect is driven by specific events is certainly a matter for future examination.

Table 4. Net effects of expansions and cutbacks in pensions in Denmark

\begin{tabular}{ccccc}
\hline & & \multicolumn{3}{c}{ Expansion events } \\
& & 0 & 1 & 2 \\
\hline \multirow{n}{*}{ Cutback events } & 1 & $-0.394^{* *}$ & 0.495 & $1.383^{*}$ \\
& 2 & $-0.788^{* *}$ & N/A & N/A \\
& 3 & $-1.183^{* *}$ & N/A & N/A \\
\hline
\end{tabular}

Note: See Table 2 for details.

Table 4 reports the net effects of reform events on government popularity, as Table 2 did for Britain. Since apparently only expansions matter in the domain of unemployment protection, and therefore there can be no counter-balancing effect, we compute the net effects only in the domain of pensions, for the cases with one to three cutbacks across scenarios with various numbers of expansions in pensions. Similar to the results we demonstrated for Britain, cutbacks with no expansions have a negative effect on support for governments in Denmark. This negative effect is neutralized by just one expansion event, and with more expansions governments get 
even more support as long as there is only a single cutback. ${ }^{44}$ All in all, governments appear to be able to compensate by combining cuts with expansions $(\mathrm{H} 2)$ both in Britain and Denmark.

Following this, we can now turn to a more systematic assessment of the negativity bias hypothesis (H3): Do cutbacks lead to stronger reactions than expansions? To capture whether the effects of cutbacks are larger than the effects of expansions, Table 5 compares the magnitude of the coefficients employing a set of Wald tests, which are reported in the last column. Note that to zero-in on the magnitude, the analyses only compare the absolute values. In three out of four tests, the difference is insignificant, while expansions of British unemployment protection are rewarded more generously than cutbacks are punished. In the latter case, it should be kept in mind that there are few expansions of British unemployment protection to begin with. At any rate, our analysis suggests that voters are not particulary harsh in punishing cutbacks compared to rewarding for expansions. That is, the negativity bias hypothesis $(\mathrm{H} 3)$ is not supported as the general response to welfare reforms in Britain and Denmark, at least.

Table 5. Wald tests of negativity bias

\begin{tabular}{llccl}
\hline & & $\begin{array}{c}\text { Magnitude: Effect } \\
\text { of cutbacks }\end{array}$ & $\begin{array}{c}\text { Magnitude: Effect of } \\
\text { expansions }\end{array}$ & Wald test \\
\hline Britain & Pensions & 1.211 & 0.705 & Cut $>$ Exp \\
\multirow{5}{*}{ Denmark } & Unemployment & 0.584 & 2.286 & Cut<Exp** \\
& Pensions & 0.394 & 0.889 & Cut<Exp \\
& Unemployment & 0.090 & 0.622 & Cut<Exp \\
\hline
\end{tabular}

\footnotetext{
${ }^{44}$ Given that Denmark has multiparty governments most of the time, it is an interesting question whether some parties in government are punished more or less than others. We have reproduced the pension models in Table 3 with support for the Prime Minister's party, instead of all parties in the government, as the outcome variable (results are reported in Table A4 in Online Appendix). Overall, the results for the effect of expansions are substantially very similar (but with slightly smaller coefficients), but the negative effects of cutbacks are even more muted than when looking at support for the whole cabinet. Compared to the results from Britain, this result might partially suggest that the relatively lower clarity of responsibility in Danish coalition governments results in less clear punishment and reward to the Prime Minister's parties. In particular, this also indicates that blame is not equally distributed (and that perhaps nor is credit).
} 
Note: The Wald-test are based on the absolute values of the coefficients for cutbacks and expansion, based on Models 2, 4, 6, and 8 in Tables 1 and 3. The entries are the absolute size of the coefficients, e.g., the effects of cutbacks are originally all in negative value. $* * p<0.01$.

Negativity bias is a well-established phenomenon in human psychology ${ }^{45}$ with documented ramifications in, for instance, media reporting. ${ }^{46}$ Given this, our findings are surprising and at odds with the expectations of Weaver and Pierson. ${ }^{47}$ So why do we not observe a negativity bias in voter reactions to reforms? One reason may be that voters do not evaluate reforms the same way they evaluate other phenomena, although this appears implausible given the pervasiveness of negativity biases in human psychology. More likely, there is something about the way in which cutbacks and expansions are implemented that dilute voters' negativity bias. Both Weaver and Pierson, in fact, point in this direction. Re-election motivated politicians may introduce cutbacks using technical, or "invisible", policy instruments thereby hiding the extent of the cuts (or whether there were any at all). Conversely, expansion may be introduced using less technical, of "visible", policy instruments. This would allow the politicians to maximize credit-claiming for expansions and minimize blame for cutbacks. If we assume that voters actually punish cutbacks harder than expansions and reforms are implemented in this way, this could explain the observed pattern. ${ }^{48}$

\section{Discussion}

Given that the welfare state is hugely popular among voters, the findings in recent studies that governments can frequently get away with cutbacks have puzzled many researchers. There can be several reasonable explanations for this phenomenon: Voters may give priority to issues other

\footnotetext{
${ }^{45}$ e.g. Rozin and Royzman 2001.

${ }^{46}$ Soroka 2006.

${ }^{47}$ Weaver 1986; Pierson 1994.

${ }^{48}$ For evidence pointing in this direction, see Jensen et al. 2017.
} 
than welfare policy reforms; they might not have a thorough understanding of what goes on in politics; or they might simply be unaware of reforms. ${ }^{49}$ Undoubtedly there is much truth in these descriptions of voters, but our aggregate-level analysis suggests that they do not tell the whole story.

First, using a more appropriate measure of welfare reforms, which assuages concerns about the measurements previously employed in the literature, we have located substantially sizable effects of cutbacks on government support. Second, we have also shown that expansions can have fairly considerable positive effects. Binding together the two findings, the net effect of reform events on government popularity can vary greatly depending on whether a given year sees only cutbacks, only expansions, or both at the same time. This suggests that much of the previous literature suffers from a misspecification problem. More interestingly, though, it also suggests that modern-day politicians have more room for maneuver than is commonly assumed. Blame avoidance is not the only game in town. Instead, there is room for a government to please voters enough to make them support it. It seems that credit-claiming never left the stage entirely.

As is evident from Figures 1-4, there are many more cutbacks occurring today than three decades ago; something that is well-documented in the literature. This reflects that governments have been forced to restructure the welfare state to meet the demands of a globalizing economy. Yet there are fundamental differences across the two programs we studied in this paper. Unemployment insurance has witnessed many more cutbacks than pensions, which have seen just as many expansions as cutbacks. As mentioned above and elsewhere in the literature, this might be because pensions are much more popular than unemployment benefits. This difference in popularity is also plainly evident in our results. Controlling for potential confounders, electoral punishment for cutting back pensions in Britain is twice as large as the punishment for cutting

\footnotetext{
49 e.g., Pierson 1994; Giger and Armingeon 2008; Giger and Nelson 2013; Elmelund-Præstekær et al. 2015.
} 
back unemployment protection. In Denmark on average there is no punishment at all for cutbacks in unemployment protection, but a substantial one for cutting pensions.

By way of conclusion, let us point to three important questions for future research. First, how is it, more exactly, that voters come to know about welfare state reforms and subsequently decide to punish the government? Voters are presumably not keeping track of new legislation by themselves. Rather, they are likely to depend on mass media communication to stay informed about developments. Welfare reforms will, all else equal, be a salient issue to report on for most media, which is probably why we find the effects we do. ${ }^{50}$ Voters generally are well enough informed to react; yet sometimes they may not be so informed. Understanding when welfare reforms become media news is, in other words, important.

Second, we found that most of the time both expansions and cutbacks lead to reactions of the same magnitude. This flies in the face of claims that voters fail to react to expansions and only focus on cutbacks. That said, expansions and cutbacks may not be implemented the same way. Following the logic of Weaver and Pierson, it is possible to hypothesize that cuts will be introduced in more subtle ways than expansions to minimize blame from the former and maximize credit-claiming from the latter. ${ }^{51}$ An interesting avenue of future research would be to study the way expansions and cutbacks are introduced and whether that may help explain why there is no difference between of the effects of cutbacks and expansions. Third, we observed some cross-country differences between Britain and Denmark. With only two countries, it is hard

\footnotetext{
${ }^{50}$ While it is beyond the scope of this study, we fully recognize the value of exploring when and how welfare reforms are reflected in media. The particular difficulty incorporating the media communication component into the current study is, to our best knowledge, the lack of fine-tuned codes focusing on the event of welfare reform legislation itself in the existing media dataset out there. Another important limitation is that existing news media archives do not cover the study period, which makes it impossible to incorporate the news coverage into our statistical model as a proxy of voter attention to reform events, e.g., Danish newspaper archive Infomedia only covers the main newspapers since 1990 and the largest newspaper 'Jyllands-Posten' only since 1996. Similarly, Lexis-Nexis and Retriever de facto only cover the years since 1996 .

${ }^{51}$ Weaver 1986; Pierson 1994.
} 
to ascribe much inferential value to such distinctions, but it is, of course, plausible that the institutional setup of these and other countries affect voters' reactions. With a larger sample of countries, it may be possible to more systematically gauge such cross-country differences. Lastly, we have explored the effects of cutbacks on voter reactions on two policy areas. An ambitious next step would be to obtain data on more areas - not simply to see if similar effects there, but to explore how reforms on one area may compensate for reforms on another. 


\section{References}

Aardal, Bernt., and van Wijnen, Pieter. 2005. "Issue Voting" in Thomassen, Jacques (ed.) The European Voter. A Comparative Study of Modern Democracies. Oxford: Oxford University Press, 192-212.

Amable, B., D. Gatti, and J Schumacher. 2006. Welfare-State Retrenchment: The Partisan Effect Revisited. Oxford Review of Economic Policy 22(3): 426-44.

Armingeon, Klaus and Nathalie Giger. 2008. Conditional Punishment: A Comparative Analysis of the Electoral Consequences of Welfare State Retrenchment in OECD Nations, 19802003. West European Politics 31(3): 558-80.

Arndt, Christoph. 2013. The Electoral Consequences of Third Way Welfare State Reforms: Social Democracy's Transformation and its Political Costs. Amsterdam: Amsterdam University Press.

Arndt, Christoph (2016): Public policy-making and risk profiles: The Scandinavian centre-right in power after the turn of the millennium. OnlineFirst in European Political Science Review.

Bawn, K., and F. Rosenbluth. 2006. Short versus Long Coalitions: Electoral Accountability and the Size of the Public Sector. American Journal of Political Science 50(2): 251-65.

Clasen, Jochen and Daniel Clegg. 2007. Levels and Levers of Conditionality: Measuring Change Within Welfare States. Pp. 166-97 in Investigating Welfare State Change: The 'Dependent Variable Problem' in Comparative Analysis, edited by J. Clasen and N. Siegel. Cheltenham: Edward Elgar.

Davidsson, Johan Bo and Paul Marx. 2013. Losing the Issue, Losing the Vote: Issue Competition and the Reform of Unemployment Insurance in Germany and Sweden. Political Studies 61(3): 505-22.

Elmelund-Præstekær, C., \& Emmenegger, P. 2013. Strategic Re- framing as a Vote Winner: Why Vote-seeking Governments Pursue Unpopular Reforms. Scandinavian Political Studies 36(1), 23-42.

Elmelund-Præstekær, C., M.B. Klitgaard, and G. Schumacher. 2015. What Wins Public Support? Communicating or Obfuscating Welfare State Retrenchment. European Political Science Review 7(03): 427-50.

Giger, Nathalie. 2011. The Risk of Social Policy? The Electoral Consequences of Welfare State Retrenchment and Social Policy Performance in OECD Countries. London and New York: Routledge. 
Giger, Nathalie and Moira Nelson. 2011. The Electoral Consequences of Welfare State

Retrenchment: Blame Avoidance or Credit Claiming in the Era of Permanent Austerity? European Journal of Political Research 50(1): 1-23.

Giger, Nathalie and Moira Nelson. 2013. The Welfare State or the Economy? Preferences, Constituencies, and Strategies for Retrenchment. European Sociological Review 29(5): 1083-94.

Green-Pedersen, C. 2004. The Dependent Variable Problem within the Study of Welfare State Retrenchment: Defining the Problem and Looking for Solutions. Journal of Comparative Policy Analysis: Research and Practice 6(1): 3-14.

Hinterleitner, M. 2015. Reconciling perspectives on blame avoidance behaviour. Political Studies Review. Early view.

Jensen, Carsten. 2014. The Right and the Welfare State. New York and Oxford: Oxford University Press.

Jensen, C., and P.B. Mortensen. 2014. Government Responses to Fiscal Austerity: The Effect of Institutional Fragmentation and Partisanship. Comparative Political Studies 47(2): 143-70.

Jensen, C., C. Arndt, S. Lee, and G. Wenzelburger. 2017. Policy Instruments and Welfare State Reform. Journal of European Social Policy. Forthcoming.

Jensen, C., and M. B. Petersen. 2017. The Deservingness Heuristic and the Politics of Health Care. American Journal of Political Science, 61(1): 68-83.

Jæger, Mads Meier. 2011. Do We All (Dis)like the Same Welfare State? Configurations of Public Support for the Welfare State in Comparative Perspective. Pp. 45-68 in Changing Social Inequality: The Nordic Model in the 21 st Century, edited by J. Kvist, J. Fritzell, B. Hvinden, and O. Kangas. Bristol: Policy Press.

Keele, L., and N.J. Kelly. 2006. Dynamic Models for Dynamic Theories: The Ins and Outs of Lagged Dependent Variables. Political Analysis 14(2): 186-205.

Korpi, W., and J. Palme. 2003. New Politics and Class Politics in the Context of Austerity and Globalization: Welfare State Regress in 18 Countries, 1975-95. American Political Science Review 97(03): 425-46.

Lewis-Beck, M., and M. Stegmaier. 2000. Economic Determinants of Electoral Outcomes. Annual Review of Political Science 3: 183-219.

Lewis-Beck, M. S., R. Nadeau, and E. Bélanger. 2004. General Election Forecasts in the United Kingdom: A Political Economy Model. Electoral Studies 23(2): 279-90. 
Lijphart, A. 1999. Patterns of Democracy: Government Forms and Performance in Thirty-Six Democracies. New Haven: Yale University Press.

Lindbom, Anders. 2014. Waking up the Giant? Hospital Closures and Electoral Punishment in Sweden. Pp. 156-177 in How Welfare States Shape the Democratic Public: Policy Feedback, Participation, Voting and Attitudes, edited by Staffan Kumlin and Isabelle Stadelmann-Steffen. Cheltenham, UK and Northampton, USA: Edward Elgar Publishing. Nannestad, P., and M. Paldam. 1994. The VP-Function: A Survey of the Literature on Vote and Popularity Functions after 25 Years. Public Choice 79(3-4): 213-45.

Pierson, Paul. 1994. Dismantling the Welfare State? Reagan, Thatcher, and the Politics of Retrenchment. Cambridge: Cambridge University Press.

Pierson, Paul. 1996. The New Politics of the Welfare State. World Politics 48(2): 143-79.

Powell Jr, G.B. and G.D. Whitten. 1993. A Cross-National Analysis of Economic Voting: Taking Account of the Political Context. American Journal of Political Science: 391-414.

Rozin, P., and E. B. Royzman. 2001. Negativity bias, negativity dominance, and contagion. Personality and Social Psychology Review 5(4): 296-320.

Sanders, D. 2005. The Political Economy of UK Party Support, 1997-2004: Forecasts for the 2005 General Election. Journal of Elections, Public Opinion and Parties 15(1): 47-71.

Schumacher, Gijs, Barbara Vis, and Kees van Kersbergen. 2013. Political Parties' Welfare Image, Electoral Punishment and Welfare State Retrenchment. Comparative European Politics 11(1): 1-21.

Scruggs, Lyle, Jahn Detlef, and Kati Kuitto. 2014. Comparative Welfare Entitlements Dataset 2. Version 2014-03. University of Connecticut and University of Greifswald.

Soroka, S. 2006. Good news and bad news: Asymmetric responses to economic information. Journal of Politics 68(2): 372-385.

Van Oorschot, W. 2006. Making the Difference in Social Europe: Deservingness Perceptions Among Citizens of European Welfare States. Journal of European Social Policy 16(1): 2342.

Vis, Barbara. 2016. Taking stock of the comparative literature on the role of blame avoidance strategies in social policy reform. Journal of Comparative Policy Analysis: Research and Practice 18(2): 122-137.

Weaver, R. Kent. 1986. The Politics of Blame Avoidance. Journal of Public Policy 6(4): 371-98. Yantek, Thom. 1985. Government Popularity in Great Britain Under Conditions of Economic Decline. Political Studies XXXIII: 467-83. 